\title{
Modelling of changes in the corneal endothelium after cataract surgery and penetrating keratoplasty
}

\author{
A K Bates, $R$ W Hiorns, $H$ Cheng
}

\begin{abstract}
Long term changes in endothelial cell density were monitored in three groups of patients after surgery. One group underwent uncomplicated cataract surgery, one group complicated cataract surgery which eventually progressed to corneal decompensation, and one group penetrating keratoplasty. A mathematical model is presented which describes endothelial cell loss after surgery as an exponential decay process towards an asymptote with constant rate of cell loss over time. When fitted to the data from the three groups there is excellent agreement in each case. Discriminant analysis techniques were applied to model predictions to assess the likelihood of late corneal decompensation after surgery. From measurements of endothelial cell density before and after surgery we were able to correctly assign patients undergoing cataract surgery to decompensation or non-decompensation groups in $\mathbf{8 5 . 7 \%}$ and $\mathbf{9 2 . 7 \%}$ of cases respectively.
\end{abstract}

The changes which occur in the corneal endothelium after cataract surgery and penetrating keratoplasty are well documented, both in terms of endothelial cell density and morphology. ${ }^{1-4}$ However little attempt has been made to assess whether these changes conform to a mathematical model and are therefore predictable. ${ }^{3} \mathrm{We}$ have previously described such a model $^{5}$ in a preliminary report. We have now extended these observations to an increased number of patients after cataract extraction and also have examined patients undergoing penetrating keratoplasty to see if they too conform to this type of mathematical model.

\section{Methods}

Three groups of patients were studied. The first two came from a randomised controlled trial of cataract surgery, ${ }^{6}$ which was commenced in 1981 , in which patients were followed for a minimum of 5 years with no loss to follow up except through death. In this trial there were 117 patients whose surgery was completely uneventful both per- and postoperatively (group 1). Some of these patients had intracapsular cataract extraction, either with or without an iris clip intraocular lens and some had extracapsular extraction with a Binkhorst 2 loop iridocapsular lens. Another group of 14 patients were identified who had complications at surgery and ultimately progressed to corneal decompensation (group 2). These patients had one or other of the intraocular lenses. The third group consisted of 25 patients with keratoconus who underwent penetrating keratoplasty at Moorfields and who have been followed with serial endothelial cell counts after.surgery (group 3).

The patients undergoing cataract surgery had endothelial cell photographs using non-contact specular microscopy, preoperatively, at 1 month, 6 months, and then yearly after surgery. Cell density was derived by counting cells within a grid of known size and masking procedures were used. The method has been described ${ }^{7}$ and its precision estimated. ${ }^{8}$

The patients undergoing penetrating keratoplasty were photographed by contact specular microscopy and density was again derived by grid counting. The first cell count was performed as soon as possible after surgery, usually within the first week, and then after $1,3,6$, and 9 months, as well as annually thereafter.

\section{STATISTICAL METHODS}

Using the endothelial cell counts for those patients who underwent uneventful surgery (group 1), the following analysis was undertaken. The mean cell count was calculated at each time point and an empirical curve of exponential type was fitted to these values. As we found in our previous work $k^{5}$ that an improved fit was obtained if an asymptote was included, this type of model was again used here to represent the number of cells which the decay process seems to be approaching. Using the best fitting empirical model allowed the prediction of cell loss directly and also provided a means of smoothing individual counts (which may be subject to sampling error) so that classification techniques could be applied to predict the long term outcome for patients following surgery.

For an individual patient, the recorded cell count values $y_{\mathrm{t}}$ at time $t$ (in months), seem to follow the model:

$$
y_{\mathrm{t}}=a+b \cdot r^{\mathrm{t}} \pm e_{\mathrm{t}}
$$

where $e_{\mathrm{t}}$ is the random error in the count (due to sampling error, difficulties in visualisation of cells etc), $a$ is the asymptotic cell count, towards which the count appears to be reducing, $b$ is the preoperative cell count in excess of $a$, and $r$ is the rate of reduction in the count per month. The model treats endothelial cell loss after surgery as an exponential decay process with a steady rate of loss over time. This type of model applies in many biological situations, for example cell loss after damage by irradiation.

Using this model and measured endothelial cell counts a cell loss curve was generated for patients in the other groups. Discriminant analysis may then be performed to see whether the curve for that patient lies closer to the curve of the group of patients who decompensated 
after cataract surgery or the curve of those that did not. It thus affords a means of predicting whether decompensation will occur. The accuracy of this technique was assessed by looking at the patients in our study who underwent cataract surgery and in whom it was known whether decompensation occurred to see how many of them were ascribed to the correct group. It was also possible to establish which of the postoperative counts in conjunction with the preoperative count gave the best prediction of the eventual outcome for a new patient.

The performance of linear and quadratic discriminant functions (LDA and QDA) were compared and the cross-validation technique was used to reduce the bias in the estimated misclassification rates for these methods. These disciminant techniques are discussed by Friedman ${ }^{9}$ and the determination of misclassification rates used here is described by Lachenbruch. ${ }^{10}$

For comparison with the above multivariate discriminant methods, a simpler graphical technique was also examined based upon the position of the plotted counts for an individual to be classified in relation to the mean curves for the groups. The patient was then allocated to the group whose curve was closest to the plotted counts for that patient. Unfortunately the results of this technique were consistently less good than those found using any of the discriminant methods. This approach was therefore not pursued.

\section{Results}

The longitudinal changes in endothelial cell density in the three groups of patients are shown in Tables 1 and 2 . The 2 year cell density value for group 3 may be erroneously low due to the small number of values at this time point. When these changes are plotted against time (Figs 1 to 3) group 2 clearly follows an exponential type curve and the other groups also follow a similar form of curve.

Simultaneous fitting of the curves to the groups produces a common asymptote value of $377 \cdot 6$ (SD 190.1). The rates of cell depletion differed for the three groups as shown by the $r$ values. For those patients developing corneal decompensation this rate was 0.949 (SD 0.016), for those in the corneal graft group it was lower at 0.971 (SD 0.006), and for the uncomplicated

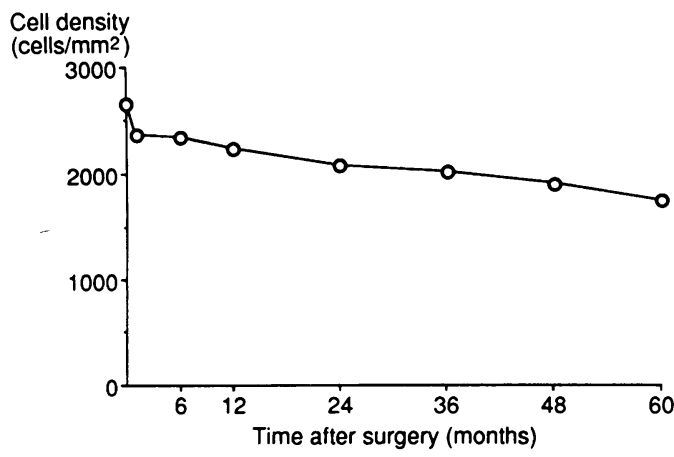

Figure 1 Pattern of change in endothelial cell density after uncomplicated cataract extraction.
Table 1 Endothelial cell density after uncomplicated and complicated cataract surgery

\begin{tabular}{lll}
\hline & $\begin{array}{l}\text { Group 1 (uncomplicated) } \\
(\text { cells/mm }\end{array}$ & $\begin{array}{l}\text { Group 2 (complicated) } \\
(\text { cells/mm })\end{array}$ \\
\hline Pre-op & 2670 SD 436 $n=117$ & 2424 SD 482 $n=14$ \\
1 month & 2378 SD 365 $n=101$ & 1986 SD 627 $n=9$ \\
6 months & 2351 SD 313 $n=112$ & 1674 SD 585 $n=14$ \\
1 year & 2244 SD 435 $n=103$ & 1206 SD 502 $n=14$ \\
2 years & 2086 SD 648 $n=97$ & 853 SD 452 $n=14$ \\
3 years & 2024 SD 685 $n=85$ & 645 SD 219 $n=11$ \\
4 years & 1916 SD 708 $n=79$ & 586 SD 233 $n=8$ \\
5 years & 1747 SD 830 $n=10$ & \\
\hline
\end{tabular}

Table 2 Endothelial cell density after penetrating keratoplasty

\begin{tabular}{ll}
\hline$\cdot$ & Group 3 $\left(\right.$ cells $\left./ \mathrm{mm}^{2}\right)$ \\
\hline Early post-op & 2548 SD 264 $n=24$ \\
1 month & 2202 SD 295 $n=21$ \\
3 months & 2114 SD 374 $n=22$ \\
6 months & 2065 SD 375 $n=23$ \\
9 months & 1938 SD 385 $n=24$ \\
1 year & 1896 SD 403 $n=21$ \\
18 months & 1775 SD 481 $n=10$ \\
2 years & 1025 SD 231 $n=3$ \\
\hline
\end{tabular}

cataract extraction group it was lowest at 0.995 (SD 0.002).

In those patients who progressed to corneal decompensation (group 2) this occurred at a mean time after surgery of $44 \cdot 6$ (SD $4 \cdot 1$ ) months. The measured endothelial cell density at the time of decompensation was 495 (SD 34) cells per $\mathrm{mm}^{2}$. This is in agreement with other studies ${ }^{112}$ and with predictions made on the basis of endothelial physiology and in particular pump site density.

Standard survival data analysis when applied to the model curve for group 2 produced a mean time to decompensation of $50 \cdot 1$ (SD 2.4) months and predicted that cell density at decompensation would be 542 (SD 36) cells per $\mathrm{mm}^{2}$ which are close to the means of the observed values.

If the model is applied to group 1, which underwent uncomplicated surgery, it predicts that these eyes too will eventually decompensate at some $\mathbf{4 7 7}$ months after surgery. This form of prediction cannot be applied accurately to the corneal graft group since it does not take into account movement of cells between donor and host tissue. When the observed longitudinal changes in endothelial cell density are compared with predicted values obtained using our model there is excellent agreement. Fig 4 shows the measured values of cell density after uncomplicated cataract extraction as open symbols while

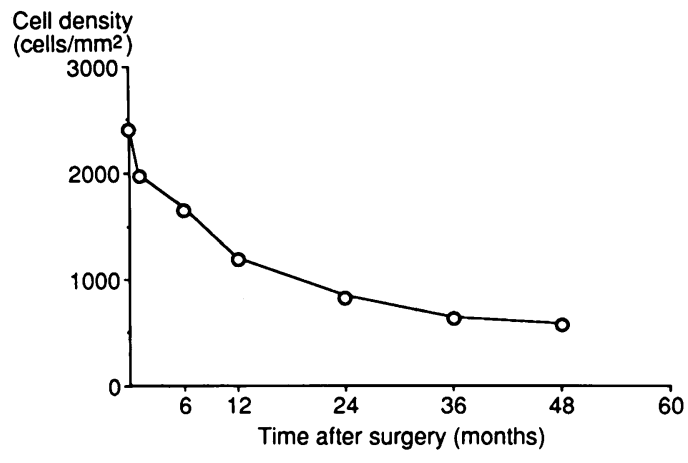

Figure 2 Pattern of change in endothelial cell density after complicated cataract extraction progressing to corneal decompensation. 


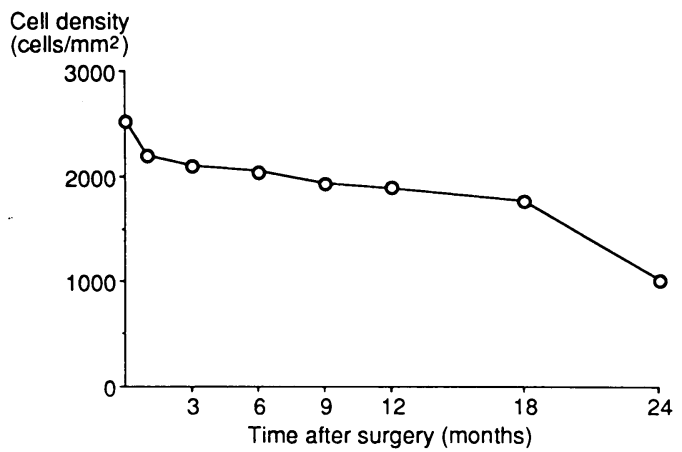

Figure 3 Pattern of change in endothelial cell density after uncomplicated penetrating keratoplasty for keratoconus.

those values predicted by the model at each time point are shown as filled symbols.

Similarly after complicated extraction progressing to corneal decompensation (Fig 5) the model predictions shown are once again very close to the values actually observed.

This close agreement also applies for the corneal graft group (Fig 6) although there may be some deviation later due to migration of host cells. Furthermore the 2 year value observed may be artificially low due to the small number of patients recorded so far at this time point.

Using the discriminant analysis techniques described the 14 patients who decompensated were examined. For this the preoperative cell count was used in conjunction with either the 1 year or 2 year cell counts or both. As shown in Table 3 the method correctly predicts that decompensation would occur in $85.7 \%$ of these patients if either or both of these time points was used.

The same procedure was then applied to patients who did not decompensate after surgery (group 1) and who had endothelial cell counts available at all time points (Table 4). Eighty seven per cent were correctly predicted not to decompensate on the basis of the 1 year count in conjunction with the preoperative count, $90.0 \%$ if the 2 year count was used, and if both values were used this rose to $92 \cdot 7 \%$ in the linear analysis.

The close agreement between the linear and quadratic methods suggests that little further improvement would be expected using Friedman's regularised discriminant analysis. Although this method was not pursued in this situation, it may well be appropriate where

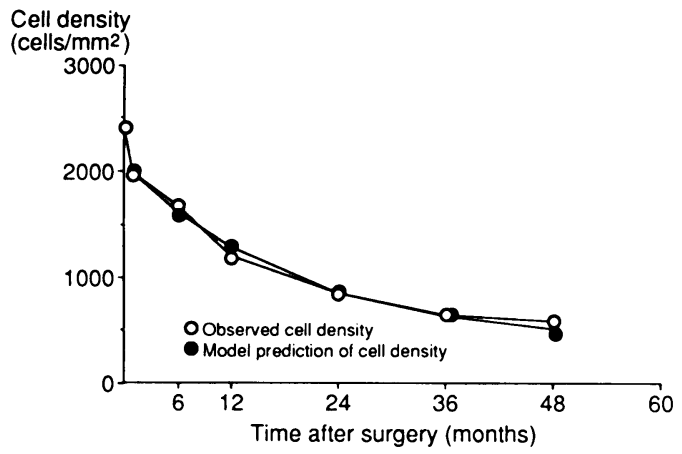

Figure 5 Comparison of model predictions and observed endothelial cell counts after complicated cataract extraction progressing to corneal decompensation.

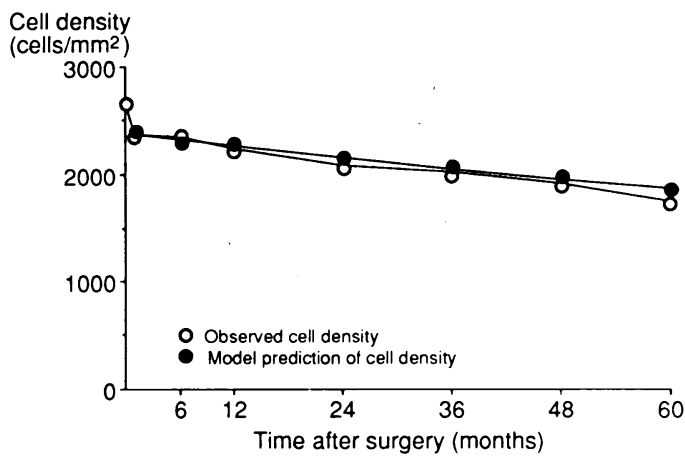

Figure 4 Comparison of model predictions and observed endothelial cell counts in uncomplicated cataract extraction.

smaller samples from more heterogeneous populations are involved.

\section{Discussion}

The values observed for decline in endothelial cell density in the three groups (Tables 1 and 2) are of similar orders of magnitude to other studies in the literature and, in the case of the first two groups, have already been fully reported.' However in this instance it was the profile of longitudinal cell loss with which we were concerned rather than the absolute values.

As in our preliminary report ${ }^{5}$ excellent agreement was found between the observed values of longitudinal endothelial cell density and those predicted by the model after both uncomplicated and complicated cataract extraction. With greater numbers of patients included the fit is improved.

This is the first time that we have examined patients after penetrating keratoplasty and it was interesting to find that there was again close agreement between observed and predicted values. We are aware of only one other attempt to model changes in the corneal endothelium after corneal grafting. ${ }^{3}$ It appears that the fit between model and actual values is less good at later time points than after cataract extraction. This is likely to reflect remodelling with movement of cells between host and donor tissue which is not presently taken into account in model predictions.

The prediction obtained, using the model, that late corneal decompensation is likely to occur eventually after even uncomplicated cataract surgery some 477 months later is inter-

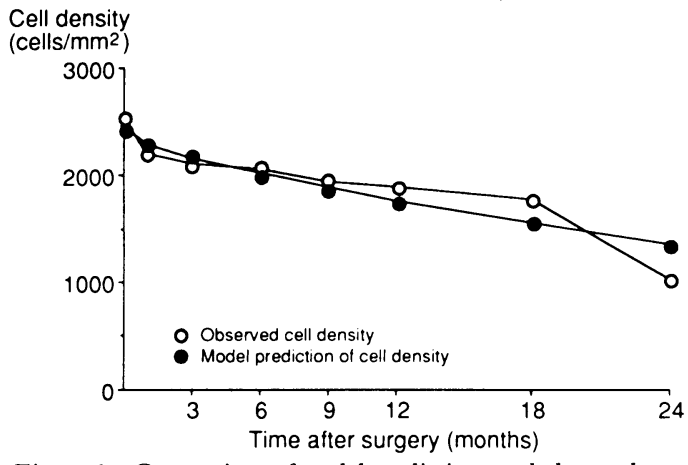

Figure 6 Comparison of model predictions and observed endothelial cell counts after uncomplicated penetrating keratoplasty for keratoconus. 
Table 3 Cross-validated error rates for the prediction of outcome using two methods of discriminant analysis for the corneal decompensation group

\begin{tabular}{|c|c|c|c|c|}
\hline & \multicolumn{2}{|c|}{ Linear analysis } & \multicolumn{2}{|c|}{ Quadratic analysis } \\
\hline & $\begin{array}{l}\text { Correctly } \\
\text { classified }\end{array}$ & $\begin{array}{l}\text { Incorrectly } \\
\text { classified }\end{array}$ & $\begin{array}{l}\text { Correctly } \\
\text { classified }\end{array}$ & $\begin{array}{l}\text { Incorrectly } \\
\text { classified }\end{array}$ \\
\hline $\begin{array}{l}\text { Pre-op+ } \\
1 \text { year } \\
2 \text { years } \\
\text { Both years }\end{array}$ & $\begin{array}{l}12(85 \cdot 7 \%) \\
12 \\
12\end{array}$ & $\begin{array}{l}2 \\
2 \\
2\end{array}$ & $\begin{array}{l}12 \\
12 \\
12\end{array}$ & $\begin{array}{l}2 \\
2 \\
2\end{array}$ \\
\hline
\end{tabular}

esting and of some concern in view of the early age at which some patients now undergo cataract extraction with or without intraocular lens implantation. It relates to the fact that, in this as in other studies, although the annual cell loss after cataract surgery levels off after approximately 4 years it continues to be slightly greater than that for an unoperated eye, in this case $0.7 \%$ versus a typical value of $0.5 \% .^{8}$ It is of course possible that eventually the cell loss will normalise absolutely such that this prediction would become incorrect, but in view of the length of follow up here and the increasing frequency of late corneal decompensation observed clinically we suspect that this may not be the case and therefore our prediction should be considered in discussing cataract surgery with young patients.

Discriminant analysis may be used in conjunction with model predictions to assess the likelihood of late corneal decompensation after surgery. When used here on those patients undergoing cataract surgery it correctly assigned $85 \cdot 7 \%$ of the eyes with bullous keratopathy to this fate using the preoperative cell counts with either the 1 year postoperative count, the 2 year count or both (Table 3 ). Those eyes which did not decompensate were correctly classified in $86.5 \%$ of cases using the preoperative and 1 year count; in $89.6 \%$ of cases using the preoperative and 2 year count; and $92 \cdot 7 \%$ of cases if both these postoperative values were used by a linear discriminant function (Table 4). The corresponding values were very similar when quadratic discriminant analysis was used.

Thus using our model in conjunction with discriminant analysis those eyes which are likely to progress to corneal decompensation can be predicted with a high degree of accuracy from only two endothelial cell counts.

We foresee a number of potential clinical applications for this type of model. As shown it may be used after surgery to predict the likelihood of progression to corneal decompensation and its time course.

At the present time there are a number of
Table 4 Cross-validated error rates for the prediction of outcome using discriminant analysis for the uncomplicated cataract surgery group

\begin{tabular}{llllll}
\hline & \multicolumn{2}{l}{ Linear analysis } & & \multicolumn{2}{l}{ Quadratic analysis } \\
\cline { 2 - 3 } \cline { 5 - 6 } & $\begin{array}{l}\text { Correctly } \\
\text { classified }\end{array}$ & $\begin{array}{c}\text { Incorrectly } \\
\text { classified }\end{array}$ & $\begin{array}{l}\text { Correctly } \\
\text { classified }\end{array}$ & $\begin{array}{l}\text { Incorrectly } \\
\text { classified }\end{array}$ \\
\hline Pre-op+ & & & & \\
1 year & $83(86 \cdot 5 \%)$ & 13 & & $84(87 \cdot 5 \%)$ & 12 \\
2 years & $86(89 \cdot 6 \%)$ & 10 & & $86(89 \cdot 6 \%)$ & 10 \\
Both years & $89(92 \cdot 7 \%)$ & 7 & $86(89 \cdot 6 \%)$ & 10 \\
\hline
\end{tabular}

clinical situations where it would be of value to be able to assess the likelihood of development of corneal decompensation, for example when considering implanting an intraocular lens in the second eye of a young patient or when performing cataract surgery on an eye with a corneal graft. It is hoped that model predictions will allow this risk to be assessed more accurately and so facilitate appropriate management.

Model predictions may also be used to give more rapid evaluation of the effects of new techniques or products used in surgery on the cornea or of different methods of storage of graft material.

In conclusion our work thus far has shown that the changes which occur in the corneal endothelium after surgery may be accurately modelled and so are predictable and we believe that this may have a number of clinical applications.

We would like to thank Mr R J Buckley for kindly allowing us to use endothelial cell counts on patients under his care after penetrating keratoplasty. We would like to thank Don Barbour for photographic assistance. Anne Ambrose for cell counting and Jane Fallows for graphics.

1 Oxford Cataract Treatment and Evaluation Team. Long-term corneal endothelial cell loss after cataract surgery. Arch Ophthalmol 1986; 104: 1170-5.

2 Liesegang TJ, Bourne WM, Ilstrup DM. Short and long term endothelial cell loss associated with cataract extraction and intracular lens implantation. Am 7 Ophthalmol 1983; 97: 32-9.

3 Bourne WM. Morphologic and functional evaluation of the endothelium of transplanted human corneas. Trans Am Ophthalmol Soc 1983; 81: 403-50.

4 Matsuda M, Suda T, Manabe R. Serial alterations in endothelial cell shape and pattern after intraocular surgery. $A m \mathfrak{F}$ thelial cell shape and pattern

5 Bates AK, Cheng H, Hiorns RW. Pseudophakic bullous keratopathy: relationship with endothelial cell density and use of a predictive cell loss model. A preliminary report. Curr Eye Res 1986; 5: 363-6.

6 Oxford Cataract Treatment and Evaluation Team. Cataract surgery: interim results and complications of a randomised controlled trial. Br $\mathcal{F}$ Ophthalmol 1986; 70: 402-14.

7 Price NC, Cheng H. Contact and non-contact specular microscopy. Br F Ophthalmol 1981; 65: 568-74.

8 Cheng H, Jacobs PM, McPherson K, Noble MJ. Precision of cell density estimates and endothelial cell loss with age. Arch Ophthalmol 1985; 103: 1478-81.

9 Friedman JH. Regularised discriminant analysis. 7 Am Stat Assoc 1989; 84: 165-75.

10 Lachenbruch P, Mickey $M$. Estimation of error rates in discriminant analysis. Technometrics 1968; 10: 1-11

11 Waring GO, Bourne WM, Edelhauser HF, Kenyon KR. The corneal endothelium. Ophthalmology 1982; 89: 531-90.

12 Mishima S. Clinical investigations on the corneal endothelium. Am f Ophthalmol 1982; 93: 1-29. 